\title{
Antonio Ximénez de Urrea y Enríquez, I marqués de Almonacir. Apuntes biográficos
}

\section{Biographical notes about the $1^{\text {st }}$ Marquis of Almonacir}

\author{
Javier ReVILLa CANORA \\ Universidad Autónoma de Madrid \\ javier.revilla@uam.es \\ https://orcid.org/0000-0001-5723-0702
}

Fecha de recepción: 19-03-2020

Fecha de aceptación: 20-05-2020

\section{RESUMEN}

Perteneciente a una de las más importantes casas del reino de Aragón -los condes de Aranda-, el marqués de Almonacir es un personaje muy poco conocido y habitualmente confundido con otros miembros de su estirpe. Hijo segundón, fue beneficiario de un título nobiliario por azares del destino y llegó a ocupar el cargo de virrey.

Con este trabajo pretendemos aportar algunos datos sobre la biografía de este noble, analizando sus orígenes familiares, su trayectoria política como virrey o sus redes intelectuales o religiosas.

Palabras clave: Marqués de Almonacir, nobleza, virrey

Topónimos: Aragón, Cerdeña, Mediterráneo,

Periodo: siglo XVII

\section{ABSTRACT}

Member of one of the most important noble households of the Kingdom of Aragon -the Earls of Aranda- the Marquis of Almonacir is a largely unknown figure who tends to be confused with other members of his family. Although not the firstborn, by a quirk of fate he obtained a noble title and became a Viceroy.

The aim of this paper is to provide some information about his biography, analysing his family origins, his political career as Viceroy and his intellectual and religious networks

Key words: Marquis of Almonacir, nobility, Viceroy

Place names: Aragon, Sardinia, Mediterranean Sea,

Period: XVII th century 


\section{INTRODUCCIÓN}

La biografía como género historiográfico ha tenido sus valedores y detractores desde el inicio de los tiempos y, en consecuencia, ha experimentado periodos de auge y momentos de crisis. Su resurgir en los últimos años no ha eliminado ese recelo, pero sí ha permitido arrojar luz sobre individuos que han sido olvidados por los historiadores con el paso del tiempo y que, con su estudio, podemos profundizar en el conocimiento de una sociedad en un momento concreto. De igual modo, el método prosopográfico se ha revelado extremadamente útil para estudiar las élites de poder, reconstruyendo sus redes familiares y clientelares, vínculos personales en aspectos artísticos o religiosos y un largo etcétera. Con estos datos, la biografía de un personaje se vuelve más compleja y rica y permite extraer nuevas conclusiones que pueden servir notablemente al conocimiento de una época concreta ${ }^{1}$.

Muchos son los grandes personajes sobre los que tenemos un profundo conocimiento de su biografía. Nobles, políticos, artistas, científicos y un largo etcétera gozan de monografías en las que se detallan todos y cada uno de los acontecimientos, por pequeños que estos sean, que marcaron su existencia y la huella que han dejado en la historia. Muchos, también, son aquellos que aún permanecen sin estudiar a pesar de haber jugado un papel principal en campos como los antes mencionados.

El objetivo del presente trabajo es llevar a cabo un sucinto análisis de un personaje concreto: Antonio Ximénez de Urrea y Enríquez, marqués de Almonacir y conde de Pavías, primer titular de ambos. Para ello, emplearemos fuentes primarias procedentes de archivos y bibliotecas las cuales, sin embargo, no han resultado suficientes en un primer acercamiento. Trataremos, además, de complementarlas con fuentes impresas y aportaciones bibliográficas recientes que nos permitirán enmarcar el objeto de estudio dentro de un contexto histórico concreto. También emplearemos piezas literarias para tratar de comprender mejor la época y la concepción que sus contemporáneos tenían de este personaje.

A través de la reconstrucción de su biografía podremos conocer el modo en que se relacionaba con la sociedad en la que vivía, al tiempo que se pone en valor los lazos sociales que desarrolló. Así, profundizar en el conocimiento de personajes como el que aquí nos ocupa puede ayudarnos en un objeto de estudio mayor: entender las dinámicas sobre el gobierno de un territorio como el reino de Cerdeña a lo largo un periodo de tiempo concreto y establecer unas conclusiones sobre el perfil de sus virreyes o la visión que de aquel tenían los gobernantes del momento.

\section{ORÍGENES FAMILIARES Y NOMBRAMIENTO COMO VIRREY}

Antonio Ximénez de Urrea y Enríquez fue hijo del III conde de Aranda y su segunda mujer, doña Juana Enríquez de Cabrera y Mendoza -hija del II duque de Medina de

1 El debate historiográfico sobre la biografía es enormemente amplio, por lo que nos remitimos al estudio clásico de C. Seco Serrano, "La biografía como género historiográfico", en Once ensayos sobre la Historia, Madrid, Fundación Juan March, 1976, pp. 105-118. También a estudios más recientes como en dossier coordinado por I. Burdiel "Los retos de la biografía", Ayer, 93 (2014), o la obra coordinada I. Burdiel, R. Foster (eds.), La historia biográfica en Europa. Nuevas perspectivas, Zaragoza, Institución Fernando el Católico, 2015. En relación a los estudios prosopográficos, vid. L. Stone, El pasado y el presente, México, Fondo de Cultura Económica, 1986, pp. 61-94. E. Soria Mesa, J. J. Bravo Caro, J. M. Delgado Barrado, Las élites en la época moderna: la Monarquía española, Córdoba, Servicio de Publicaciones de la Universidad de Córdoba, 2009. J. Martínez Millán, "Los estudios sobre élites de poder y la Corte", en Élites y poder en las monarquías ibéricas. Del siglo XVII al primer liberalismo, Madrid, Biblioteca Nueva, 2013, pp. 17-36. B. Yun Casalilla (coord.), Las redes del imperio: élites sociales en la articulación de la Monarquía Hispánica, 1492-1714, Madrid, Marcial Pons, 2009. 
Rioseco y VI Almirante de Castilla-. El matrimonio se llevó a efecto el 29 de junio de 1564 en la ciudad de Valladolid y fruto del cual nacieron cinco seis hijos, uno de los cuales, nuestro personaje ${ }^{2}$.

Aunque desconocemos la fecha exacta del nacimiento del marqués de Almonacir, lo cierto es que el primer tercio del siglo XVII fue el periodo en el que creció y maduró. Así, el Aragón de Felipe III es un periodo poco conocido, a caballo entre dos hitos históricos que lo han oscurecido: los sucesos de 1591 y las cortes de Barbastro de 1626. Sin embargo, las tensiones sociales y políticas derivadas del primero se mantuvieron durante las primeras décadas del Seiscientos, aunque rebajadas por el paso del monarca por las ciudades de Teruel y Zaragoza tras su boda con Margarita de Austria en el reino de Valencia. En estos años, Aragón experimentó un reverdecer cultural con la proliferación de cenáculos académicos y literarios tema que, como tantos de este reino, permanecen aún con más sombras que luces.

Parece que la nobleza aragonesa tuvo un renovado interés por la corte real durante este periodo, y varios de sus miembros pudieron ocupar puestos de relevancia en la administración de la Monarquía del periodo. En este sentido cabría destacar al conde de Sástago, al marqués de Camarasa o al duque de Híjar, además de los herederos del duque de Villahermosa y, en menor medida, del conde de Aranda. Estos últimos formaban parte de las principales familias del reino de Aragón, un antiguo linaje que había perdido peso en la corte tras la participación del IV conde en las alteraciones del reino de Aragón en tiempos de Felipe II y que paulatinamente fueron recuperando prestigio. Con la llegada al trono de Felipe III la situación de la casa de Aranda mejoró al concederse un perdón real y los bienes de esta, antes confiscados, pudieron ser empleados de nuevo. Finalmente, en 1640 fueron nombrados Grandes de España ${ }^{3}$.

La condesa de Aranda, doña Juana, se esforzó en obtener para sus hijos una importante dotación patrimonial aun a costa del primogénito de la casa, lo que se tradujo en una relación complicada con el heredero de su esposo ${ }^{4}$. Sin embargo, logró que su marido constituyese un nuevo mayorazgo con la adquisición de la baronía de la Vall de Almonacid, que se transformó en marquesado de Almonacir y condado de Pavías durante las cortes aragonesas de $1626^{5}$. Así mismo, llevó a cabo una importante política matrimonial al casar a sus hijos con miembros de importantes linajes: su hija mayor, Mariana, contrajo matrimonio con el IV conde de Sástago; el mayor de los varones, Pedro, casó con Lucrecia de Moncada, hija del II marqués de Aytona; por último, nuestro personaje, Antonio, desposó a Francisca de Moncada, prima de Lucrecia e hija de Hugo de Moncada -hermano del II marqués de Aytona-y de Dionisia Queralt -hermana del I marqués de Santa Coloma- ${ }^{6}$.

2 El árbol genealógico del marqués de Almonacir se conserva en Real Academia de la Historia, (RAH), Salazar y Castro 9/296, fol. 199v. Habitualmente se le suele confundir con su sobrino, el V conde de Aranda, por tener ambos el mismo nombre y primer apellido. L. Malo Barranco, Nobleza en femenino. Mujeres, poder y cultura en la España moderna, Madrid, Centro de Estudios Políticos y Constitucionales, 2018, p. 309.

3 J. Gascón Pérez, "El reino de Aragón a principios del siglo XVII", en La monarquía de Felipe III, Madrid, Polifemo, 2008, vol. 4, pp. 173-195 y 405-407. Sobre la participación de los miembros de la casa de Aranda vid. J. Gascón Pérez, La rebelión aragonesa de 1591, tesis doctoral, Zaragoza, 2000, pp. 1120 y ss. Citamos, así mismo, los estudios clásicos de G. Colás Latorre, J. A. Salas Ausens, Aragón en el siglo XVI, Zaragoza, Prensas de la Universidad de Zaragoza, 1982; E. Solano, Poder monárquico y Estado pactista (1626-1652), Zaragoza, Institución Fernando el Católico, 1987.

4 J. Gascón Pérez, Alzar banderas contra su rey. La rebelión aragonesa de 1591 contra Felipe II, Zaragoza, Prensas Universitarias de Zaragoza, 2010, p. 474.

5 A. Ramos, Aparato para la corrección y adición de la obra que publicó en 1769 el doctor don José Berní y Catalá, Málaga, Impresor de la dignidad Episcopal, 1777, p. 83.

6 L. Malo Barranco, Nobleza en femenino..., pp. 313 y ss.; J. Gascón Pérez, Alzar banderas..., p. 472. 
Antonio Ximénez de Urrea y Enríquez fue nombrado por Felipe IV como virrey de Cerdeña el 30 de enero de 1632, con un salario que consistía en tres mil ducados anuales más otros tres mil de ayuda de costa, suponiendo un montante anual de seis mil ducados anuales $^{7}$. A diferencia de otros virreyes, no disponemos de información sobre su viaje 0 su llegada al reino. También desconocemos si anteriormente había ocupado algún cargo político o militar.

¿Qué situación se encontró Almonacir a su llegada a Cerdeña? Los años veinte del Seiscientos en este reino comenzaron con el gobierno del barón de Benifayró, Juan Vivas de Cañamás, quien había ejercido el cargo de embajador en Génova durante más de dos décadas ${ }^{8}$. Su trienio en el reino insular se caracterizó por una tensa relación con diversos sectores de la sociedad, condicionado por los propios intereses pecuniarios del valenciano, que chocaron frontalmente con los derechos y prácticas locales ${ }^{9}$. Tras su inesperado fallecimiento en Cagliari, Felipe IV nombró al marqués de Bayona para sustituirle.

El nuevo virrey tuvo que reconducir esta situación. Además, debió presidir dos parlamentos del reino, marcados por las campañas bélicas que la monarquía protagonizó en el contexto de la Guerra de los Treinta $A \tilde{n} \mathrm{~s}^{10}$. Bayona logró obtener unas condiciones inmejorables para reconducir la malograda situación interna que dejó el virrey Vivas y concluir unas sesiones de Cortes -1626 y 1631- que fuesen propicias a las oligarquías locales, a las arcas del reino y a los objetivos políticos que se perseguían desde Madrid. Sin embargo, igual que su predecesor, falleció inesperadamente el 15 de abril de 1631. La interinidad fue ejercida por el obispo de Alguero, Gaspar Prieto, quien, además, debió encargarse de la clausura del Parlamento que aún estaba abierto ${ }^{11}$.

\section{OBJETIVOS ECONÓMICOS DE SU GOBIERNO}

Una vez llegó a Cagliari, Almonacir tuvo que enfrentarse especialmente a los problemas de recaudación de dinero debido a las numerosas peticiones pecuniarias que se habían realizado en los últimos años desde Madrid. Así mismo, se vio en serios aprietos para cumplir con los envíos. El historiador Francesco Manconi llegó a afirmar que el condeduque de Olivares amenazó con destituirle si no cumplía con las directrices que se le habían pedido ${ }^{12}$.

Tan trabajosa era la tarea que el Consejo de Aragón decidió encargar al Dr. Francisco Castro, juez de Corte del reino sardo, que investigase cómo y cuándo habían salido las

7 Archivo Histórico provincial de Zaragoza (AHPZ), P/4-083-04.

8 M. Á. Ochoa Brun, Historia de la diplomacia española, Madrid, Ministerio de Asuntos Exteriores, 2003, vol. VII, pp. 123 y 142-143. Su nombramiento como virrey se encuentra en Archivo Histórico Nacional (AHN), Consejos, libro (lib.) 2559, folios (fols.) 126r-143r.

9 Un sucinto panorama del gobierno de Vivas en Cerdeña lo encontramos en N. Verdet Martínez, "Autoritarismo regio y representatividad parlamentaria. El discurso de Francisco Jerónimo de León acerca del parlamento celebrado en el Reino de Cerdeña en el año 1624", en Campo y campesinos en la España Moderna. Culturas políticas en el mundo Hispano, León, Universidad de León-CSIC, 2012, vol. II, pp. 1707-1718.

10 Sobre este conflicto nos remitimos al trabajo de C. Borreguero Beltrán, La Guerra de los treinta Años, 1618-1648. Europa ante el abismo, Madrid, Esfera de los Libros, 2018. Aquí se puede encontrar un completo y actualizado estado de la cuestión. Los Parlamentos han sido estudiados en G. Tore, II Parlamento strordinario del viceré Gerolamo Pimentel marchese di Bayona (1626), Cagliari, CUEC, 1998. G. Tore, Il Parlamento del viceré Gerolamo Pimentel marchese di Bayona e Gaspare Prieto, presidente del Regno, Cagliari, CUEC, 2007.

11 Sus instrucciones se conservan en AHN, Consejos, lib. 2561, fols. 249v-266v.

12 F. Manconi, Cerdeña. Un reino de la Corona de Aragón bajo los Austrias, Valencia, Servicio de Publicaciones de la Universitat de València, 2010, p. 380. 
diversas partidas de dinero del reino. El cometido resultó enormemente complicado tanto por la complejidad de las operaciones llevadas a cabo para la recaudación como, sobre todo, por la imprecisión documental relativa a las recaudaciones ${ }^{13}$.

Almonacir no sólo tuvo que tratar de resolver las dificultades antedichas, sino que debió hacer frente a los problemas derivados de los asientos firmados, especialmente, con comerciantes ligures en connivencia con algunos potentados sardos, para quienes el control de la producción frumentaria del reino era fundamental a la hora de mantener sus haciendas ${ }^{14}$. Una parte de la élite local no estaba de acuerdo con la política de asientos llevada a cabo por la corona en el reino. Así, en 1633, la ciudad de Sassari envió una embajada a Madrid, al frente de la cual situó a Alonso de Gualbes y Zúñiga -marqués de Palmas y representante del estamento militar-, con el propósito de negociar varios asuntos, entre los que destacaba el tema de los asientos y la reserva de los cargos del reino para los naturales. En sus propias palabras, sin embargo, su propósito "no se hará ajustado a mi deseo". Con todo, subraya que buena parte de los logros que obtuvo fueron gracias al regente $\mathrm{Vico}^{15}$.

Las levas de soldados continuaron durante sus años de gobierno, pues la guerra aún no había terminado. Cerdeña debía volver a contribuir con hombres y dinero, que fueron destinados a las campañas en la península italiana: nobles, prelados y otros potentados volvieron a financiar la creación de un tercio de infantería del que una parte significativa estaba formada por gentes de mal vivir tanto del campo como de los entornos urbanos, lo que sirvió para paliar la delincuencia y atenuar la presión social de las capas más peligrosas. Pablo de Castelví -marqués de Cea y procurador real de la Audiencia sarda- pagó, así mismo, una importante suma para situarse a la cabeza de dicho tercio y poder integrar en él a personas de su máxima confianza, como su propio hijo, Jorge de Castelví ${ }^{16}$.

Durante este primer trienio como virrey, Almonacir tuvo que desarrollar una política de venta de cargos, oficios e incluso títulos nobiliarios auspiciada por las instrucciones que el regente del Consejo de Aragón, Francisco de Vico, había llevado consigo al reino de Cerdeña ${ }^{17}$. El objetivo último no era novedoso, pues las cantidades recaudadas irían destinadas a pagos militares de los frentes de Italia y, sobre todo, de Cataluña. El arrendamiento de las almadrabas del reino, el oficio de gobernador del Océano, el asiento de las sacas de legumbres, el arrendamiento de la nieve de la ciudad de Cagliari o el veguerato de Oristano fueron algunos de los cargos que se vendieron. Sin embargo, el título de marqués de Soleminis fue de los más deseados. Tanto, que fue el propio regente Vico quien lo adquirió ${ }^{18}$.

Durante los siguientes años, las obligaciones de Vico en el reino de Cerdeña comenzaron a ser cuestionadas por otros ministros reales. Además, su parcialidad hacia los intereses

13 AHN, Consejos, lib. 2562, fols. 227r-234r, correspondientes a la instrucción del juez de corte.

14 F. Manconi Cerdeña. Un reino..., p. 383.

15 Archivo de Congreso de los Diputados (ACD), Archivo de Cerdeña, legajo (leg.) 15, documento (doc.) 244.

16 AHN, Consejos, lib. 2562, fols. 160r y ss. Una biografía de este personaje puede leerse en L. Gómez Orts, J. Revilla Canora "Al servicio del rey en las cortes de Cagliari, Valencia y Madrid: Jorge de Castelví y Melchor sisternes", en Cagliari and Valencia during the Baroque Age. Essays on Art, History and Literature, Valencia, Albatros, 2016, pp. 45-72.

17 AHN, Consejos, lib. 2562, 20 de julio de 1635. Sobre el regente vid. F. Manconi, "Un letrado sassarese al servicio della Monarchia ispanica. Appunti per una biografia di Francesco Angel Vico y Artea", en Sardegna, Spagna e Mediterraneo, Roma, Carocci, 2004, pp. 291-333.

18 AHN, Consejos, leg. 18825, exp.18. 
de personas e instituciones del norte del reino eran manifiestos, lo que provocó numerosas quejas por parte de las élites cagliaritanas. Vico llegó a recibir acusaciones relacionadas con la concesión de favores y títulos nobiliarios a cambio de notables sumas económicas y, sobre todo, la de haber fomentado las diferencias existentes entre el norte y el sur -entre las ciudades de Cagliari y Sassari- y sus elites con el objetivo último de mantener su posición y preeminencia, además de fortalecer sus lazos clientelares ${ }^{19}$. Su suerte política cambió con la caída de Olivares. Varios ministros sardos propusieron al nuevo valido, Luis de Haro, que se jubilase a Vico para poder así nombrar un nuevo regente del reino ${ }^{20}$. Sin embargo, no se llegó a llevar a cabo, pues el regente sardo falleció en Madrid en $1648^{21}$.

\section{CUESTIONES MILITARES: LA DEFENSA DE CERDEÑA}

Almonacir desarrolló una importante política de reconstrucción y mejora del sistema defensivo insular prácticamente desde su llegada al reino. Esta iniciativa fue elogiada en la dedicatoria que Jusepe Ginobart le brindó en una edición de la obra Diálogo de la verdadera honra militar:

y apenas llegó a él, año de 1632, cuerdamente mandó que se fortificasen todas las ciudades y, plazas más importantes, que estaban sin defensa, reparándose y abasteciéndose todas de pertrechos bélicos y de víveres, para que de esta suerte estuvieran preparadas para cualquier invasión que intentaran los enemigos de la monarquía española ${ }^{22}$

Desde el Consejo de Aragón se consideró que Almonacir estaba desarrollando un buen gobierno en la isla pues el 2 de junio de 1635 le confirmó como virrey de Cerdeña durante otro trienio ${ }^{23}$. Ese año fue crucial para el reino en el contexto de la Guerra de los Treinta Años, pues Francia se incorporó al conflicto. Así, la isla pasó a ser un punto de retaguardia que mantendría su función de aprovisionar de hombres y víveres. Tras su regreso a Madrid, Francisco de Vico procuraba que el reino obtuviese el mayor beneficio posible de la fidelidad mostrada a la política de Felipe IV en materia de guerra.

Durante el gobierno del virrey Vivas de Cañamás (1623-1625), el gobernador de Milán avisó sobre la posible amenaza del litoral sardo debido a la cercanía de una flota francesa ${ }^{24}$. En septiembre de 1636 se avistó una flota gala cerca de las costas del reino ${ }^{25}$. Ante esta noticia, Almonacir tomó una serie de decisiones relativas a la defensa: se realizaron tareas de fortificación tanto en la costa como en el interior, se organizaron las provisiones bélicas y se procuró de reorganizar la milicia de una manera más eficiente ${ }^{26}$. Además, el virrey

19 F. Manconi, Cerdeña. Un reino..., pp. 389-395.

20 F. Manconi, "Un letrado sassarese...", pp. 318 y ss.

21 J. Arrieta Alberdi, "Vico y Artea, Francisco de", en Diccionario Biográfico Español, on-line [http://dbe.rah. es/biografias/43281/francisco-angel-vico-y-artea] (Consulta: 14-05-2020).

22 J. Ginovart, "Al Excelentísimo Señor Don Antonio Jiménez de Urrea y Enríquez, marqués de Almonacid y conde de Pavías, del Consejo de Su Majestad, Virrey y Capitán General que fue del Reino de Cerdeña" en Diálogo de la verdadera honra militar, Venecia, 1566, edición Biblioteca Virtual Miguel de Cervantes, 1992. [http://www.cervantesvirtual.com/obra-visor/dialogo-de-la-verdadera-honra-militar--0/html/] (Consulta: 19-32020). La dedicatoria está firmada en Zaragoza, 20 de noviembre de 1642.

23 AHPZ, P/4-083-04

24 G. Sorgia, Mire francesi sulla Sardegna nel 1638, Padova, CEDAM, 1957, p. 7.

25 Se habían tenido avisos de varios avistamientos de la flota francesa anteriores al ataque de 1637. Vid. Biblioteca Nacional de Cataluña (BNC), F. Bon, 7683, Carta de aviso a un caballero de esta ciudad, de la entrada de los franceses en la ciudad de Oristan, Barcelona, 1637.

26 Sobre las milicias del reino, C. Mora Casado, Las milicias en el Mediterráneo occidental. Valencia y 
procuró informarse de la posición de las embarcaciones enemigas, al tiempo que solicitó que se enviasen al reino sardo galeras procedentes de las escuadras Nápoles, Sicilia o Génova para que previniesen un posible ataque ${ }^{27}$. Varias galeras genovesas acudieron a la llamada del virrey y permanecieron durante algún tiempo en el puerto de Cagliari.

Todo el Mediterráneo estaba vigilante y las noticias procedentes de diversos lugares de la Monarquía llegaban de manera fluida y eficiente. Los vecinos reinos de Nápoles y Sicilia se encontraban en alerta por si debían proporcionar ayuda ante un posible ataque sobre Cerdeña ${ }^{28}$. Desde Barcelona, se envió una dotación de 6.000 infantes para guarnecer los reinos de Mallorca y Cerdeña ${ }^{29}$.

La tensión se rompió el 21 de febrero de 1637, durante las celebraciones del carnaval. Una flota francesa liderada por el conde de Harcourt y el arzobispo de Burdeos apareció frente a las costas de la ciudad de Oristano ${ }^{30}$. Las autoridades de la ciudad enviaron noticias del ataque al virrey, quien convocó los Consejos de Justicia, Patrimonio y Guerra del reino para gestionar la situación. Almonacir decidió enviar noticia tanto al Consejo de Aragón como a los vecinos reinos de Nápoles y Sicilia para que enviasen refuerzos. Ordenó, así mismo, la movilización inmediata de todas las fuerzas militares del reino y situó en el mando a Diego de Aragall, gobernador de cabo de Cagliari y teniente general del reino ${ }^{31}$. Desde el norte de la isla se solicitó socorro al embajador de España en Génova y al gran duque de Toscana. Este último envió en un cortísimo plazo de tiempo varios centenares de libras de pólvora ${ }^{32}$.

Por último, Almonacir encargó la defensa de la capital a Diego Duque de Estrada ${ }^{33}$. Así, llevó a cabo la limpieza del foso, la reparación de la muralla, empalizó las puertas de acceso y se encargó de proveer de municiones y vituallas la ciudad, además de implicar activamente al clero cagliaritano ${ }^{34}$.

Cerdeña en la época de los Austrias, Cagliari-Valencia, tesis doctoral, 2016.

27 E. Jiménez Pablo, "Jiménez de Urrea y Enríquez, Antonio", Diccionario Biográfico Español, on-line [http:// dbe.rah.es/biografias/41836/antonio-jimenez-de-urrea-y-enriquez] (Consulta: 19-3-2020). V. Cipollone, La politica navale della Spagna nel fronte mediterraneo (1635-1678). Cagliari, 2012, tesis doctoral.

28 Real Biblioteca del Palacio Real de Madrid (RB), II/2552, fols. 45r-46v.

29 RB, II/2552, fols. 69r-71v. Sobre el envío de naves desde Nápoles para el socorro de Cerdeña vid. BR, II/2552, fols. $17 \mathrm{r}, 20 \mathrm{v}, 33 \mathrm{r}$ y $38 \mathrm{v}$.

30 A. Canales de Vega, Invasión de la armada francesa, Cagliari, 1637. En Madrid también se publicó una relación sobre el episodio: Biblioteca Nacional de España (BNE), VE, 186/50, Relación de la entada de los franceses en la ciudad de Oristano. F. Manconi, "L'invasione di Oristano nel 1637: un'occasione di patronazgo real nel quadro della guerra ispano-francese", Società e storia, 84 (1999), pp. 253-279. J. Revilla Canora, "La Guerra de los Treinta Años en el Mediterráneo: la sombra francesa sobre Cerdeña", Manuscrits. Revista d'història moderna, 38 (2018), pp. 73-90.

31 G. de Caro, "Aragall, Diego de", Dizionario Biografico degli italiani, on-line [http://www.treccani.it/ enciclopedia/diego-de-aragall_(Dizionario-Biografico)] (Consulta: 19-3-2020).

32 G. Mele, Documenti sulla difesa militare della Sardegna in eta spagnola, Sassari, Fondazione Banco di Sardegna, 2006.

33 N. Bazzano, "'Un fraile injerto en soldado'. La difesa del Regno di Sardegna nei Comentarios del desengañado de sí mismo di Fray Justo de Santa Maria, dell'Ordine degli Ospedalieri di San Giovanni di Dio, già don Diego Duque de Estrada", Dimensioni e problemi della ricerca storica, I, (2018), pp. 169-186, especialmente p. 178.

34 D. Duque de Estrada: Comentarios del desengañado de sí mismo. Vida del mismo autor, H. Ettinghausen (ed.), Madrid, Castalia, 1983, pp. 467, 482-483; A. Cioppi, "Fra' Giusto di Santa Maria. Da nobile guerriero a frate ingegnere nella Cagliari del XVII secolo", en Centri di potere nel Mediterraneo occidentale. Dal Medioevo alla fine dell'Antico Regime, Milan, Franco Angelli, 2018, p. 167. 
La invasión francesa fue el principal acontecimiento al que tuvo que hacer frente el marqués de Almonacir durante su gobierno en el reino de Cerdeña. El ataque se saldó de manera favorable y el virrey pudo continuar con su actividad normal hasta que fue nombrado el príncipe de Melfi en su lugar.

El nuevo virrey llegó al puerto de Cagliari con una escuadra formada por catorce galeras. Realizó el tradicional recorrido hacia el Palacio Real en el que fue recibido por el virrey interino, los representantes de la ciudad, los nobles y caballeros del reino y demás personas ilustres a la par que se fueron desarrollando los festejos derivados de su nombramiento ${ }^{35}$. Tras jurar su cargo en la catedral, Melfi continuó la estela iniciada por Almonacir: se ocupó de aprovisionar las galeras, proveer plazas de capitanes y otros mandos militares y trató de organizar el material de guerra existente en el reino, pues los ecos del ataque francés de 1637 aún resonaban en el imaginario sardo ${ }^{36}$.

\section{LA MARQUESA DE ALMONACIR EN ZARAGOZA}

Durante los seis años que el marqués de Almonacir ejerció como virrey de Cerdeña, su mujer, doña Francisca de Moncada, permaneció en Zaragoza. Tras haber gobernado dos trienios el reino de Cerdeña, la marquesa escribió a su sobrino, el II conde de Santa Coloma, una carta -fechada del 2 de febrero de 1638- en la que mostraba su estupefacción ante la noticia del nombramiento del príncipe de Melfi como nuevo virrey. Doña Francisca manifestaba su preocupación, ya que algunos sobrinos que residían en Madrid le habían transmitido las noticias sobre la continuidad de su marido en el cargo por un tercer trienio ${ }^{37}$.

Unos días más tarde -el 16 de febrero-, la marquesa volvió a escribir a Santa Coloma para felicitarle tras conocer la noticia de su nombramiento como virrey de Cataluña. En esa misma carta, retomó su preocupación ante la salida de su marido del gobierno de Cerdeña, manifestando la esperanza de la intercesión de sus sobrinos para lograr un puesto para él. Doña Francisca, al mismo tiempo, aconsejó a Santa Coloma que emplease los servicios de Bernabé Camacho de Carbajal, quien ejercía como agente de los marqueses de Almonacir en Madrid, durante los años en los que estuviese alejado de la corte ${ }^{38}$. Siguiendo esta línea, el marqués, que también mantuvo correspondencia con su sobrino, propuso a Santa Coloma que tuviese cerca de su persona a otro de los deudos de la familia Ximénez de Urrea -Dr. Domingo Descartín- pues, además, había servido bien a otros importantes ministros como Fernando de Borja, el marqués de los Vélez o Juan Fernández de Heredia ${ }^{39}$. Descartín, de origen zaragozano, había ejercido diversos cargos en la administración aragonesa antes de ocupar el de abogado fiscal y patrimonial y desarrollar importantes lazos políticos y familiares en el reino de Aragón ${ }^{40}$.

La correspondencia entre la marquesa de Almonacir y el conde de Santa Coloma era fluida; no sólo hablaban de cuestiones políticas sino también de asuntos familiares. Así, desde Barcelona se informaba del crecimiento del heredero del conde y de algunas

35 J. Aleo, Storia cronológica del regno di Sardegna dal 1637 al 1672, F. Manconi (ed.), Nuoro, lliso, 1998, p. 95.

36 J. Mateu Ibars, Los virreyes de Cerdeña. Fuentes para su estudio, Padua, CEDAM, 1967, tomo II, pp. 41 y ss.

37 Archivo de la Corona de Aragón (ACA), Generalitat, correspondencia del virrey conde de Santa Coloma, carta 544.

38 Ibídem, cartas 609 y 617.

39 Ibídem, carta 6855.

40 J. I. Gómez Zorraquino, Patronazgo y clientelismo. Instituciones y ministros reales en el Aragón de los siglos XVI y XVII, Zaragoza, Prensas de la Universidad de Zaragoza, 2016, pp. 369-371. 
negociaciones llevadas a cabo en Madrid, seguramente referidas a sus esponsales. Sobre esto, la marquesa afirmó que dada la edad del futuro conde "no corre prisa el trato de la materia, pues la edad no las da". También expresaba la buena relación entre ella y la marquesa de los Vélez quien, además, estaba junto a su marido, el virrey de Aragón sobrino de doña Juana, igual que Santa Coloma-. En esta misma carta de 7 de septiembre de 1638, manifestaba su angustia por el elevado número de días en que no había recibido noticia alguna de su marido, quien parece que aún no había salido de Cerdeña ${ }^{41}$.

La intranquilidad aún tardó un mes en disiparse, pero, por fin, el 5 de octubre de 1638, la marquesa de Almonacir informaba que su marido había llegado "con buena salud a gozar del descanso de su casa, con que estoy contentísima". Por las palabras deducimos que su marido partió de Cerdeña rumbo a Barcelona y que allí fue recibido por Santa Coloma: "díjome el marqués la merced que Vuestra Excelencia le ha hecho", mostrando nuevamente la unión que existía entre ambas casas ${ }^{42}$.

Esta buena sintonía también se reflejaba en las acostumbradas felicitaciones como la Pascua o la fluida correspondencia que el heredero del conde de Santa Coloma mantenía con el marqués de Almonacir por aquellas fechas ${ }^{43}$.

\section{RESIDENCIA EN LA CIUDAD DEL EBRO}

Desde Zaragoza, los marqueses seguían puntualmente los sucesos políticos que protagonizaba su sobrino en Barcelona, haciendo especial referencia al asedio de la fortaleza de Salses, en el Rosellón ${ }^{44}$. La marquesa manifestó abiertamente el júbilo que había sentido ante la noticia de la toma de la ciudad:

Con mucho alborozo doy a V. E. la enhorabuena del suceso de Salsas en que tanta parte tengo del gusto que a V. E. habría causado como apasionada en verle fuera del cuidado que traía consigo la dilación del sitio donde corría tantos riesgos la salud con lo riguroso del tiempo. Lo que ahora querría es que V. E. tratase de retirarse al descanso de su casa para olvidar las incomodidades tan dilatadas que ha padecido ${ }^{45}$

La preocupación por su estado de salud, sus problemas en el gobierno de Cataluña, además de reiterar la idea que este regresase a su casa, muestran la profunda unión que existía entre ambas familias.

Tanto doña Francisca como el virrey, tras su regreso de Cagliari, llevaron a cabo una importante tarea de promoción de aquellas personas que formaban parte de su red clientelar, especialmente sus deudos. Así, en la mayoría de las cartas de esta correspondencia, los marqueses solicitaban mercedes o protección para religiosos, militares y juristas, muchos de los cuales habían servido a Almonacir durante sus años de gobierno de Cerdeña ${ }^{46}$.

La correspondencia con Santa Coloma se vio interrumpida tras su asesinato, ocurrido

41 ACA, Generalitat, correspondencia del virrey conde de Santa Coloma, carta 2495.

42 Ibídem, carta 2670.

43 Ibídem, cartas 3202, 3203, 8123 y 8513.

44 Ibídem, cartas 2495, 6218 y 8123 . F. M. de Melo, Historia de los movimientos, separación y guerra de Cataluña, Lisboa, 1645 [http://www.cervantesvirtual.com/obra-visor/historia-de-los-movimientos-separaciony-guerra-de-cataluna-en-tiempo-de-felipe-iv--0/html/feee546c-82b1-11df-acc7-002185ce6064_2.html\#l_1_]. (Consulta: 19-3-2020). R. Camarero Pascual, La guerra de recuperación de Cataluña (1640-1652), Madrid, Actas, 2015, pássim. D. Maffi, En defensa del Imperio. Los ejércitos de Felipe IV y la guerra por la hegemonía europea (1635-1659), Madrid, Actas, 2014, pp. 61-76.

45 ACA, Generalitat, correspondencia del virrey conde de Santa Coloma, carta 8686.

46 Ibídem, cartas 455, 474, 2495, 3235, 3377, 3378, 3379, 6824, 6855, 7887, 8034, 8282, 8728 у 9325. 
el 7 de junio de 1640 en la ciudad de Barcelona. A partir de ese momento sólo tenemos una referencia del marqués de Almonacir. Fue receptor de una carta en la que se le informaba sobre la inundación que sufrió la ciudad de Zaragoza el 18 de febrero de 1643, debido a las Iluvias y la fuerte crecida del Ebro. En ella se cuenta pormenorizadamente el avance de las aguas, que llegaron a anegar la iglesia metropolitana. A pesar de ello, algunas zonas de la ciudad no se vieron afectadas y, entre ellas, las casas del marqués de Almonacir ${ }^{47}$. Debido a lo detallado de la descripción de los desastres causados por la avenida y el hecho de informar sobre el estado en que se encontraba la casa del marqués, entendemos que este no se encontraba en Zaragoza en aquel momento.

Los marqueses de Almonacir estaban perfectamente integrados en los círculos intelectuales de la ciudad aragonesa. En primer lugar, su sobrina, la condesa de Aranda, fue una ilustre escritora cuya temática principal, que no única, fue de modelo de comportamiento de nobles ${ }^{48}$. Además, la familia Ximénez de Urrea gozaba de relaciones eruditas que traspasaban los Pirineos y les permitieron estar al tanto de las novedades científicas que allí se producían, de la mano de intelectuales como François Filhol, canónigo de Toulouse. Es más, al marqués de Almonacir le fue dedicada la obra Diseño de la insigne y copiosa biblioteca de Francisco Filhol, presbítero y hebdomadario en la santa iglesia metropolitana del protomártir san Esteban, de la ciudad de Tolosa. En ella se presenta al marqués "no solo como protector de las buenas letras sino como a varón estudioso"49.

De la misma forma, tanto los marqueses como algunos miembros de su casa mantuvieron una estrecha relación con el erudito Vicencio Juan de Lastanosa, gracias a quien pudieron conocer los gustos franceses en materia de jardinería -entre otras materias-, lo que les llevó a seguir la moda del vecino reino hasta el punto de recurrir a jardineros galos para embellecer sus casas ${ }^{50}$.

Este círculo intelectual se entremezclaba con la religiosidad de la familia. Así, su cercanía a la orden del Carmelo se establecía a través de dos vías. La primera, el propio confesor de la marquesa de Almonacir, fray Jerónimo de San José, quien fue, además, escritor e historiador ${ }^{51}$. Subrayamos también la relación personal que mantenía doña Juana

47 Archivo Histórico de la Universidad de Sevilla (AHUS), A 112/043 (05) bis, Copia de carta escrita por don Pablo de Eusa y Escarate al Excelentísimo señor marqués de Almonacir y conde de Pavías, en que le refiere la venida e inundación del río Ebro y el daño que ha hecho a la ciudad de Zaragoza, 26 de febrero de 1643.

48 Luisa María de Padilla y Manrique de Acuña, cuñada del duque de Uceda. A. Egido, "La nobleza virtuosa de la condesa de Aranda, doña Luisa de Padilla, amiga de Gracián", Archivo de filología aragonesa, 54-55 (1998), pp. 9-41; M. Torremocha Hernández, “'Lagrimas de la nobleza' o lágrimas por la nobleza. Luisa de Padilla, condesa de Aranda, y su 'reformación de nobles'”, en Campo y campesinos en la España Moderna. Culturas políticas en el mundo hispánico, León, Fundación Española de Historia Moderna/Universidad de León, 2012 vol. 2, pp. 2187-2198. M. L. Acquier, "Cultura nobiliaria, prestigio familiar y política. La producción libresca de Luisa de Padilla y la grandeza de los Urrea: evaluación de una relación compleja (1617-1644)", Librosdelacorte.es, 6 (2013), pp. 174-181.

49 J. F. Andrés de Uztarroz, Diseño de la insigne y copiosa biblioteca de Francisco Filhol, presbítero y hebdomadario en la santa iglesia metropolitana del protomártir san Esteban, de la ciudad de Tolosa, Huesca, 21 de marzo de 1644. Una copia se encuentra digitalizada en la Biblioteca Pública de Huesca, (BPH), B-10015728 [http://bibliotecavirtual.aragon.es/bva/i18n/consulta/registro.cmd?id=1576].

50 J. Pérez Magallón, Construyendo la modernidad: la cultura española en el tiempo de los novatores (1675-1725), Madrid, CSIC, 2002, p. 306. Sobre el humanista y su tiempo vid. A. Egido y J. E. Laplana Gil (eds.), Mecenazgo y Humanidades en tempos de Lastanosa. Homenaje a la memoria de Domingo Ynduráin, Zaragoza, Institución Fernando el Católico, 2008.

51 Así aparece reflejado en el testamento de la marquesa de Almonacir, AHPZ, P/4-113-27. Sobre el confesor, vid. J. Vicente Rodríguez, "Ezquerra de Rozas, Jerónimo", en Diccionario Biográfico Español, on-line [http:// dbe.rah.es/biografias/15919/jeronimo-ezquerra-de-rozas] (Consulta: 19-3-2020). 
Enríquez -condesa de Aranda y madre del marqués de Almonacir-, con la religiosa Feliciana Eufrosina de San José. Precisamente será la condesa de Aranda una de sus más firmes valedoras, pues no solamente le ayudó a entrar en religión, sino que fue la encargada de sufragar su fiesta de toma de velo. Este vínculo establecido con doña Juana -fallecida en 1599- se mantuvo también con sus hijos y nietos, especialmente con el marqués de Almonacir y con sus sobrinas, las hijas de los condes de Sástago, cuya educación estuvo a cargo del marqués ${ }^{52}$.

La última información de que disponemos sobre Almonacir es la referente a su testamento, fechado el 19 de mayo de 1643, además de dos codicilos de 6 de mayo y de 19 de octubre de 1644. Unos días más tarde, el 24 de octubre de 1644 falleció en su casa de Zaragoza, donde lo hallaron muerto en el suelo. Para llevar a cabo los procedimientos pertinentes en este tipo de situaciones, acudió a casa del marqués el notario Miguel Juan de Montaner junto con varios testigos: uno de los pajes del difunto -Jusepe de Collantesy un escribiente -Pedro Mateo de Escurpí-, además del religioso Francisco Ximénez de Urrea, familia del fallecido, capellán de Felipe IV y cronista del reino de Aragón ${ }^{53}$. Todos ellos reconocieron en acto público que el cadáver correspondía con la persona del marqués, "sin espíritu de vida [...] y no otro alguno puesto en lugar de aquel" ${ }^{54}$. Al morir sin descendencia, su hermana, la condesa de Sástago, se convirtió en la II marquesa de Almonacir ${ }^{55}$.

\section{CONCLUSIÓN}

Antonio Ximénez de Urrea y Enríquez, perteneciente a una importante casa nobiliaria -Grandes de España desde 1640-, era un segundón a quien enviaron al reino insular con el objetivo de llevar a cabo un gobierno continuista, apoyando los planes que desde Madrid se orquestaban y, al mismo tiempo, integrando a unas elites deseosas de sentirse parte de una monarquía poderosa.

Durante sus dos trienios como virrey, el marqués tuvo que hacer frente a importantes problemas pecuniarios para ayudar al mantenimiento de la política exterior de Felipe IV. Fue, sobre todo, el encargado de paliar la pésima situación en la que se encontraban los bastiones, fortines, torres de vigilancia, castillos y plazas fuertes del reino. Así, trató de pertrecharlas de la forma más conveniente con los escasos recursos de que disponía, además de procurar crear y mejorar los efectivos militares presentes en el reino. Gracias a sus esfuerzos en estos empeños, el reino de Cerdeña pudo hacer frente al poderoso enemigo francés que desembarcó en sus costas y conquistó la ciudad de Oristano en el contexto de la Guerra de los Treinta Años.

52 M. C. Marín Pina, "El escrito oculto, las redes y la construcción autorial de Feliciana de San José (Recreación espiritual, 1645)", en Autor en construcción. Sujeto e institución literaria en la modernidad hispánica (siglos XVI-XIX), Zaragoza, Prensas de la Universidad de Zaragoza, 2019, pp. 153 y ss. En este trabajo se puede encontrar un interesante gráfico sobre la red de relaciones de la religiosa. Sobre las prácticas devocionales de los miembros de la familia Ximénez de Urrea vid. L. Malo Barranco, "Los espacios de religiosidad y la devoción femenina en la nobleza moderna. El ejemplo de los linajes Aranda e Híjar", Cuadernos de Historia Moderna 42, 1 (2017), pp. 175-193. Sobre las relaciones entre la espiritualidad carmelita y la política vid. J. Martínez Millán, "La ideología religiosa de la Monarquía Católica", en La Corte de Felipe IV (1621-1665). Reconfiguración de la Monarquía Católica, Madrid, Polifemo, 2017, T. III, Vol. 3, pp. 1536 y ss.

53 Una breve referencia biográfica se puede encontrar en J. Martínez Millán y J. E. Hortal Muñoz (dirs), La corte de Felipe IV (1621-1665). Reconfiguración de la Monarquía católica, Madrid, Polifemo, 2015, T. II, p. 2156. Sobre los servicios prestados por este personaje vid. RAH, Salazar y Castro, H-25, fol. 215.

54 El testamento se conserva en AHPZ, P/4-113-26-1. Los codicilos, en AHPZ, P/4-113-26-2

55 A. Valladares de Sotomayor, Semanario erudito que comprehende varias obras inéditas, morales, instructivas, políticas, históricas, satíricas y jocosas de nuestros mejores autores antiguos y modernos, Madrid, 1790, T. XXXIII, p. 250. 
Tras su regreso de Cagliari no hemos encontrado documentación que atestigüe la concesión de algún tipo de merced o cargo al servicio de la Monarquía, aunque en la correspondencia conservada entre la marquesa doña Juana y el conde de Santa Coloma sí se pueden intuir ciertas esperanzas en este sentido ${ }^{56}$. A pesar de ello, en la corte de Zaragoza desarrollaron una importante red de contactos eruditos que les permitieron conocer de primera mano y participar en los avances más novedosos de la época. Por ello, creemos que el trabajo en archivos y bibliotecas aragoneses podría sacar a la luz nueva documentación que nos ayude a completar los aspectos biográficos que sucintamente hemos expuesto en el presente trabajo.

\section{BIBLIOGRAFÍA}

Acquier, M. L., "Cultura nobiliaria, prestigio familiar y política. La producción libresca de Luisa de Padilla y la grandeza de los Urrea: evaluación de una relación compleja (1617-1644)", Librosdelacorte.es, 6 (2013), pp. 174-181.

Aleo, J., Storia cronológica del regno di Sardegna dal 1637 al 1672, F. Manconi (ed.), Nuoro, Iliso, 1998.

Andrés de Uztarroz, J. F., Diseño de la insigne y copiosa biblioteca de Francisco Filhol, presbítero y hebdomadario en la santa iglesia metropolitana del protomártir san Esteban, de la ciudad de Tolosa, Huesca, 1644.

Arrieta Alberdi, J., "Vico y Artea, Francisco de", Diccionario Biográfico Español, on-line.

Bazzano, N., "'Un fraile injerto en soldado'. La difesa del Regno di Sardegna nei Comentarios del desengañado de sí mismo di Fray Justo de Santa Maria, dell'Ordine degli Ospedalieri di San Giovanni di Dio, già don Diego Duque de Estrada", Dimensioni e problemi della ricerca storica, I, (2018), pp. 169-186.

Borreguero Beltrán, C., La Guerra de los treinta Años, 1618-1648. Europa ante el abismo, Madrid, Esfera de los Libros, 2018.

Burdiel, I., Dossier "Los retos de la biografía", Ayer, 93 (2014).

Burdiel, I., Foster, R., (eds.), La historia biográfica en Europa. Nuevas perspectivas, Zaragoza, Institución Fernando el Católico, 2015.

Camarero Pascual, R., La guerra de recuperación de Cataluña (1640-1652), Madrid, Actas, 2015.

Caro, G. de, "Aragall, Diego de", Dizionario Biografico degli italiani, on-line.

Cioppi, A., "Fra' Giusto di Santa Maria. Da nobile guerriero a frate ingegnere nella Cagliari del XVII secolo", en Centri di potere nel Mediterraneo occidentale. Dal Medioevo alla fine dell'Antico Regime, Milan, Franco Angelli, 2018, pp. 161-168.

Cipollone, V., La politica navale della Spagna nel fronte mediterraneo (1635-1678, . Cagliari, tesis doctoral, 2012.

Colás Latorre, G., Salas Ausens, J. A., Aragón en el siglo XVI, Zaragoza, Prensas de la Universidad de Zaragoza, 1982.

Duque de Estrada, D., Comentarios del desengañado de sí mismo. Vida del mismo autor, H. Ettinghausen (ed.), Madrid, Castalia, 1983.

Egido, A., "La nobleza virtuosa de la condesa de Aranda, doña Luisa de Padilla, amiga de Gracián", Archivo de filología aragonesa, 54-55 (1998), pp. 9-41.

Egido, A. y Laplana Gil, J. E. (eds.), Mecenazgo y Humanidades en tempos de Lastanosa. Homenaje a la memoria de Domingo Ynduráin, Zaragoza, Institución Fernando el Católico, 2008.

Gascón Pérez, J., La rebelión aragonesa de 1591, tesis doctoral, Zaragoza, 2000.

56 ACA, Generalitat, correspondencia del virrey conde de Santa Coloma, cartas 9182 y 9325. 
- Alzar banderas contra su rey. La rebelión aragonesa de 1591 contra Felipe II, Zaragoza, Prensas Universitarias de Zaragoza, 2010.

- "El reino de Aragón a principios del siglo XVII", en La monarquía de Felipe III, Madrid, Polifemo, 2008, vol. 4, pp. 173-196.

Ginovart, J., "Al Excelentísimo Señor Don Antonio Jiménez de Urrea y Enríquez, marqués de Almonacir y conde de Pavías, del Consejo de Su Majestad, Virrey y Capitán General que fue del Reino de Cerdeña" en Diálogo de la verdadera honra militar, Venecia, 1566, edición Biblioteca Virtual Miguel de Cervantes, 1992.

Gómez Orts, L., Revilla Canora. J., "Al servicio del rey en las cortes de Cagliari, Valencia y Madrid: Jorge de Castelví y Melchor Sisternes", en Cagliari and Valencia during the Baroque Age. Essays on Art, History and Literature, Valencia, Albatros, 2016, pp. 4572.

Gómez Zorraquino, J. I., Patronazgo y clientelismo. Instituciones y ministros reales en el Aragón de los siglos XVI y XVII, Zaragoza, Prensas de la Universidad de Zaragoza, 2016.

Jiménez Pablo, E., “Jiménez de Urrea y Enríquez, Antonio”, Diccionario Biográfico Español, on-line.

Maffi, D., En defensa del Imperio. Los ejércitos de Felipe IV y la guerra por la hegemonía europea (1635-1659), Madrid, Actas, 2014.

Malo Barranco, L., "Los espacios de religiosidad y la devoción femenina en la nobleza moderna. El ejemplo de los linajes Aranda e Híjar", Cuadernos de Historia Moderna, 42, 1 (2017), pp. 175-193.

- Nobleza en femenino. Mujeres, poder y cultura en la España moderna, Madrid, Centro de Estudios Políticos y Constitucionales, 2018.

Manconi, F., "L'invasione di Oristano nel 1637: un'occasione di patronazgo real nel quadro della guerra ispano-francese", Società e storia, 84 (1999), pp. 253-279.

- "Un letrado sassarese al servicio della Monarchia ispanica. Appunti per una biografia di Francesco Ángel Vico y Artea", en Sardegna, Spagna e Mediterraneo, Roma, Carocci, 2004, pp. 291-333.

- Cerdeña. Un reino de la Corona de Aragón bajo los Austrias, Valencia, Servicio de Publicaciones de la Universitat de València, 2010.

Marín Pina, M. C., "El escrito oculto, las redes y la construcción autorial de Feliciana de San José (Recreación espiritual, 1645)", en Autor en construcción. Sujeto e institución literaria en la modernidad hispánica (siglos XVI-XIX), Zaragoza, Prensas de la Universidad de Zaragoza, 2019, 153-182.

Martínez Millán, J. y Hortal Muñoz, J. E. (dirs), La corte de Felipe IV (1621-1665). Reconfiguración de la Monarquía católica, Madrid, Polifemo, 2015, tomo II, p. 2156.

Martínez Millán, J., "La ideología religiosa de la Monarquía Católica", en La Corte de Felipe IV (1621-1665). Reconfiguración de la Monarquía Católica, Madrid, Polifemo, 2017, tomo III, Vol. 3, pp. 1536 y ss.

- "Los estudios sobre élites de poder y la Corte", en Élites y poder en las monarquías ibéricas. Del siglo XVII al primer liberalismo, Madrid, Biblioteca Nueva, 2023, pp. 1736.

Mateu Ibars, J., Los virreyes de Cerdeña. Fuentes para su estudio, Padua, CEDAM, 1967, tomo II.

Mele, G., Documenti sulla difesa militare della Sardegna in eta spagnola, Sassari, Fondazione Banco di Sardegna, 2006.

Melo, F. M. de, Historia de los movimientos, separación y guerra de Cataluña, Lisboa, 1645.

Mora Casado, C., Las milicias en el Mediterráneo occidental. Valencia y Cerdeña en la época de los Austrias, Cagliari-Valencia, tesis doctoral, 2016. 
Ochoa Brun, M. Á., Historia de la diplomacia española, Madrid, Ministerio de Asuntos Exteriores, 2003, vol. VII.

Pérez Magallón, J., Construyendo la modernidad: la cultura española en el tiempo de los novatores (1675-1725), Madrid, CSIC, 2002.

Ramos, A., Aparato para la corrección y adición de la obra que publicó en 1769 el doctor don José Berní y Catalá, Málaga, Impresor de la dignidad Episcopal, 1777.

Revilla Canora, J., "La Guerra de los Treinta Años en el Mediterráneo: la sombra francesa sobre Cerdeña", Manuscrits. Revista d'història moderna, 38 (2018), pp. 73-90.

Seco Serrano, C., "La biografía como género historiográfico", en Once ensayos sobre la Historia, Madrid, Fundación Juan March, 1976, pp. 105-118.

Solano, E., Poder monárquico y Estado pactista (1626-1652), Zaragoza, Institución Fernando el Católico, 1987.

Sorgia, G., Mire francesi sulla Sardegna nel 1638, Padova, CEDAM, 1957.

Soria Mesa, E., Bravo Caro, J. J., Delgado Barrado, J. M., Las élites en la época moderna: la monarquía española, Córdoba, Servicio de publicaciones de la Universidad de Córdoba, 2009.

Stone, L., El pasado y el presente, México, Fondo de Cultura Económica, 1981.

Tore, G., II Parlamento strordinario del viceré Gerolamo Pimentel marchese di Bayona (1626), Cagliari, CUEC, 1998.

- Il Parlamento del viceré Gerolamo Pimentel marchese di Bayona e Gaspare Prieto, presidente del Regno, Cagliari, CUEC, 2007.

Torremocha Hernández, M., “'Lágrimas de la nobleza' o lágrimas por la nobleza. Luisa de Padilla, condesa de Aranda, y su 'reformación de nobles'", en Campo y campesinos en la España Moderna. Culturas políticas en el mundo hispánico, León, Fundación Española de Historia Moderna/Universidad de León, 2012 vol. 2, pp. 2187-2198.

Valladares de Sotomayor, A., Semanario erudito que comprehende varias obras inéditas, morales, instructivas, políticas, históricas, satíricas y jocosas de nuestros mejores autores antiguos y modernos, Madrid, 1790, tomo XXXIII.

Verdet Martínez, N., "Autoritarismo regio y representatividad parlamentaria. El discurso de Francisco Jerónimo de León acerca del parlamento celebrado en el Reino de Cerdeña en el año 1624", en Campo y campesinos en la España Moderna. Culturas políticas en el mundo Hispano, León, Universidad de León-CSIC, 2012, T. II, pp. 1707-1718.

Vicente Rodríguez, J., "Ezquerra de Rozas, Jerónimo", en Diccionario Biográfico Español, on-line.

Yun Casalilla, B. (coord.), Las redes del imperio: élites sociales en la articulación de la Monarquía Hispánica, 1492-1714, Madrid, Marcial Pons, 2009. 